Guest Editorial

\title{
Horsemanship, dogmanship and humanship
}

A paper published recently in The Veterinary Journal by Elyssa Payne of the University of Sydney, and her colleagues, summarises skills that veterinary teams should possess in order to improve their interactions with horses or dogs and outlines how they should demonstrate these skills to clients and how to improve owner handling of animals (Payne et al., 2015). Moderating the state of arousal and promoting a positive affective state in an animal are means to improve not only the safety of the people involved, but also the welfare of the animal and the degree of satisfaction of the client.

Payne et al. (2015) describe desirable attributes of veterinarians, such as consistent behaviour, building on previous learning history of the animal, decreased positive punishment and increased reward. These characteristics are supported by peerreviewed evidence and the predicted direction of the influences of these attributes on the affective state or arousal of the animal. The authors state that animals might interpret incorrectly some signals given by humans; indeed, patting or hugging a dog or horse will not always be appreciated by the recipient as pleasant. Emulating grooming (stroking in a dog or grooming at the withers in a horse; Feh and de Mazières, 1993) is far more likely to be interpreted as pleasant, although not by animals that have not been socialised to humans.

An animal's socialisation status can be seen as a part of the outcome of learning history, which is of the utmost importance. Insufficient socialisation is serious and the effects can be long lasting (Scott and Fuller, 1965; Appleby et al., 2002) and may strongly affect the animal's capacity to cope in human society. Veterinarians should be able to recognise a socialisation status deficiency in a patient; panic reactions or freezing are understandable if one tries to approach or touch an animal that is inadequately socialised.

Veterinarians need to take a holistic view when seeing a patient. Unfortunately, veterinary and human specialists sometimes tend to investigate and treat an illness rather than the patient. Behavioural aspects, such as chronic stress resulting from management or poor housing conditions, can lead to medical problems like cystitis in cats (Stella et al., 2013) but are more likely to be overlooked when the focus is wrong. To communicate horsemanship and dogmanship, we must be able to stimulate owners to correct their behaviours towards the animal without creating defiance. Such behaviours might include inappropriate punishing or rewarding actions; punishment often works and quickly, although its effects may be temporary and sometimes ineffective (Church, 1963). Veterinarians must develop an insight into the disastrous effects that wrongly applied punishments may have; for example, punishing a dog while eating can lead to fear of eating (Lichtenstein, 1950).
Sometimes it is necessary to explain that the 'punishment' owners apply in fact reinforces the unwanted behaviours. This was shown by both Holz and Azrin (1962) and Ayllon and Azrin (1966). The risk of increasing unwanted behaviours by punishment is probably greater in animals that show a need for attention. It is important to recognise that humans often express negative emotions while punishing an animal (Xiao and Houser, 2005) and in doing so may go beyond the aim of getting the animal to stop a certain behaviour as they are too busy trying to diminish their own negative feelings. This response can very easily lead to badly timed, unjust or harsh punishments that go beyond the point when the animal has stopped its unwanted behaviour. Such subtleties have to be explained to owners in a clear way while at the same time providing clear alternatives.

These considerations oblige veterinarians to estimate the sensitivity of their patient to potentially punishing events, and to assess the (very wide) degree of understanding, softness, hardness, consistency and mental or physical power that individual owners may have. Such estimations could lead to the conclusion that there is a misfit between dog and owner(s) and that trying to rectify it requires the owners to act contrary to their own natural inclinations. In such circumstances, the advice should be to rehome an animal instead of trying to attempt behavioural therapy. In other words, veterinarians need to have an insight into the behavioural tendencies of owners as well as of their animals and take into account the opinions, prejudices and attitudes of the owners. One could call this 'additional skill humanship'.

'Humanship' should enable veterinarians to question delicate matters such as a bad relationship between owner partners that may impact upon the welfare of the animals at home. There are no data on this subject, but there are cases concerning dogs that have been shown to be anxious in the house but not outside the domestic environment. In some of these cases frequent rows between the partners occurred, which led to nervousness in the dogs; some dogs seem to interpret yelling as a punishment for its own behaviours. In fact, the dog's reaction is probably unrelated to any conflict between partners but an unpredictable (and uncontrollable) domestic tension may have arisen and this may jeopardise the welfare of the dog. To discuss this openly with the owner(s) demands considerable social capabilities and communication skills by the veterinarian.

Even with application of good horsemanship and dogmanship, it is sometimes hard to assess whether or not changes in animal handling do impact on the animal in a positive way. Weber's Law and its derivatives (Thurstone, 1927) predicts that a change in a particular condition will not be detected if it is smaller than 
a certain fraction of the original magnitude of the condition. Since this law has a general application in humans, owners may be slow to notice improvements in problem behaviour resulting from an intervention. Wahler and Leske (1973) demonstrated this in an experiment where teachers had to detect the improving problem behaviour of children. With animals, when only slow improvement is expected, veterinarians should inform owners about the need for patience and encourage them to measure progress by some simple means so preventing frustration by applying 'humanship'.

Payne et al. (2015) have provided stimulating and interesting evidence of horsemanship and dogmanship and their application in veterinary contexts; their conclusions are worthy of careful consideration and implementation by veterinarians in clinical practice.

Matthijs B.H. Schilder Claudia M. Vinke

Department of Animals in Science and Society, Faculty of Veterinary Medicine, Utrecht University, PO Box 80178,

3508 TD Utrecht, The Netherlands. E-mail address: m.b.h.schilder1@uu.nl

\section{References}

Appleby, D.L., Bradshaw, J.W.S., Casey, R.A., 2002. Relationship between aggressive and avoidance behaviour by dogs and their experience in the first six months of life. Veterinary Record 150, 434-438.

Ayllon, T., Azrin, N.H., 1966. Punishment as a discriminative stimulus and conditioned reinforcer with humans. Journal of the Experimental Analysis of Behavior 9, 411-419.

Church, R.M., 1963. The varied effects of punishment on behavior. Psychological Review 70, 369-402.

Feh, C., de Mazières, J., 1993. Grooming at a preferred site reduces heart rate in horses Animal Behaviour 46, 1191-1194.

Holz, W., Azrin, N.H., 1962. Interactions between the discriminative and aversive properties of punishment. Journal of the Experimental Analysis of Behavior 5, 229-234.

Lichtenstein, P.E., 1950. Studies of anxiety: I. the production of a feeding inhibition in dogs. Journal of Comparative Physiology and Psychology 43, 16-29.

Payne, E., Boot, M., Starling, M., Henshall, C., McLean, A., Bennett, P., McGreevy, P., 2015. Evidence of horsemanship and dogmanship and their application in veterinary contexts. The Veterinary Journal 204, 247-254.

Scott, J.P., Fuller, J.L., 1965. Dog Behavior, the Genetic Basis. University of Chicago Press.

Stella, J., Croney, C., Buffington, T., 2013. Effects of stressors on the behavior and physiology of domestic cats. Applied Animal Behaviour Science 143, 157-163.

Thurstone, L.L., 1927. A law of comparative judgement. Psychological Review 34 273-286.

Wahler, R.G., Leske, G.L., 1973. Accurate and inaccurate observer summary reports. Journal of Nervous and Mental Diseases 156, 386-394.

Xiao, E., Houser, D., 2005. Emotion expression in human punishment behavior. Proceedings of the National Academy of Sciences of the United States of America 102, 7398-7401. 